\section{Original Article}

D) Check for updates

\title{
Incidence and Clinical Characteristics of Ischemic Stroke Patients with Underlying Cancer
}

Soon Woo Kwon, Won Jun Meng, Hae in Lee, Doo Young Kim, Sung-Bom Pyun

\section{HIGHLIGHTS}

- Ischemic stroke (IS) patients with cancer showed different distribution of common cancer types with adenocarcinoma being the most common histology.

- Adenocarcinoma patients showed different relations with conventional stroke risk factors and multi territorial infarction was more common.

- IS patients with cancer had poor mortality outcome and it was influenced by systemic metastasis, multi-territorial infarction and initial neurological severity. 


\section{Original Article}

Check for updates

\section{OPEN ACCESS}

Received: Mar 23, 2019

Revised: Apr 18, 2019

Accepted: May 24, 2019

Correspondence to

Sung-Bom Pyun

Department of Physical Medicine and

Rehabilitation, Korea University Medical

Center, 73 Inchon-ro, Seongbuk-gu,

Seoul 02841, Korea.

E-mail: rmpyun@korea.ac.kr

Copyright (c) 2019. Korea Society for

Neurorehabilitation

This is an Open Access article distributed under the terms of the Creative Commons Attribution Non-Commercial License (https:// creativecommons.org/licenses/by-nc/4.0) which permits unrestricted non-commercial use, distribution, and reproduction in any medium, provided the original work is properly cited.

\section{ORCID iDs}

Soon Woo Kwon (D)

https://orcid.org/0000-0001-9366-7274

Won Jun Meng (iD)

https://orcid.org/0000-0002-8886-7105 Hae in Lee (1D)

https://orcid.org/0000-0002-4076-7762

Doo Young Kim (D)

https://orcid.org/0000-0003-1327-5348

Sung-Bom Pyun (iD)

https://orcid.org/0000-0002-1933-038X

\section{Funding}

This work was supported by the National Research Foundation of Korea (NRF) grant funded by the Korea government (MSIT) (No. 2019R1A2C2003020)

\section{Incidence and Clinical Characteristics of Ischemic Stroke Patients with Underlying Cancer}

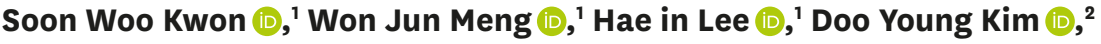 \\ Sung-Bom Pyun (iD) ${ }^{1,3}$ \\ 'Department of Physical Medicine and Rehabilitation, Korea University Medical Center, Seoul, Korea \\ ${ }^{2}$ Department of Physical Medicine and Rehabilitation, Catholic Kwandong University International St. \\ Mary's Hospital, Incheon, Korea \\ ${ }^{3}$ Brain Convergence Research Center, Korea University, Seoul, Korea
}

\begin{abstract}
Cancer and ischemic stroke (IS) are leading causes of death and disability, worldwide. It is reported that cancer increases IS incidence with various unknown mechanism. We retrospectively reviewed medical records of single tertiary medical center between January 2012 and December 2016. A total of 40,047 patients with cancer were analyzed and 63 patients $(0.16 \%)$ were diagnosed of IS with underlying cancer. Lung $(27.0 \%)$, gastric $(14.3 \%)$ and colorectal $(12.7 \%)$ cancers were the most frequent types of cancers and adenocarcinoma was the most common histologic type. We compared the clinical variables (demographic data, comorbidities, cancer stage, infarction pattern and severity) between adenocarcinoma and non-adenocarcinoma groups. And the results showed low coexistence of dyslipidemia and smoking history, and higher rate of multiple vascular territory infarct in adenocarcinoma group $(\mathrm{p}<0.05)$. Six-month post stroke mortality rate was $34.6 \%$ and systemic metastasis and multiterritorial infarction were significantly relevant with the six-month mortality $(\mathrm{p}<0.001)$. Also, initial National Institute of Health Stroke Scale $(p<0.05)$ and modified Rankin Scale scores were statistically significantly worse in mortality group $(\mathrm{p}<0.05)$. In conclusion, the most frequent cancer type was lung cancer and adenocarcinoma the most common histologic type. Mortality at 6-month post stroke was high, and it was associated with stage of cancer and initial neurological severity.
\end{abstract}

Keywords: Cancer; Ischemic Stroke; Adenocarcinoma; Mortality

\section{INTRODUCTION}

With total population of 51 million and average life expectancy of 82 years, Statics Korea reported 22,745 deaths were due to stroke and 78,863 deaths were due to cancer in South Korea in 2017 [1]. Cancer and stroke are among the three most common causes of death, both of which lead to enormous health and economic burdens.

Although cancer and stroke have distinct etiologies, correlation between them are being studied. In an autopsy study from 1985 , ischemic stroke (IS) was the second most common brain lesion in cancer patients and $14.6 \%$ of cancer patients had pathologic evidence of 
Conflict of Interest

The authors have no potential conflicts of interest to disclose. cerebrovascular disease [2]. Many studies have clarified the relationship between cancer and IS but the specific mechanism and disease characteristics are still elusive.

In 1865, Trousseau described the clinical association between idiopathic venous thromboembolism (VTE) and malignancy [3]. In a previous study, the risk for thromboembolism was up to sevenfold higher in the cancer patients [4]. And also, thromboembolism has been proven to be one of the complications of anticancer treatment, such as chemotherapy. This thrombophilia in cancer patients seems to play an important role in the development of cancer-related stroke. It has been demonstrated that the high risk of VTE in cancer patients also increases the risk of arterial thrombosis, such as IS [5]. The adenocarcinoma, which often is the most common histologic type in stroke with underlying cancer, was also associated with the increased risk of thromboembolism [6].

The neuroimaging characteristics of stroke can provide important clues to a physician. Many studies have demonstrated its role in estimating the clinical outcomes and the etiology of stroke on top of diagnosing stroke itself. Neuroimaging features of stroke with underlying cancer has been described in previous studies and multiple vascular territory infarction pattern was often more commonly encountered in cancer related stroke $[7,8]$.

The mortality outcome seems to be more severe in stroke patients with underlying cancer: the median survival was 4.5 months and one-fourth of the patients died within one month after stroke [9]. In an observational study, 1,542 (12.3\%) of the total 12,565 patients had died within 1 year after hospitalization for the acute stroke [10].

However, the diagnostic, therapeutic consensus and the prognostic factors of cancer-related stroke has not been set yet. This study is aimed to investigate the incidence, mortality and characteristics of IS patients with underlying cancer.

\section{MATERIALS AND METHODS}

We retrospectively reviewed the medical records (clinical, pathologic and radiographic) of a single medical center between January 2012 and December 2016. The 40,047 patients were diagnosed with cancer and 150 patients were diagnosed with both IS and cancer diagnosis. Following patients were excluded: 1) patients who were diagnosed with IS prior to cancer diagnosis, 2) brain tumor patients, and 3) patients with omitted initial assessment records. Among the 150 patients, 63 patients were enrolled in the study: 87 were excluded due to the above reasons. The types of cancer that led to IS, cerebrovascular risk factors (diabetes mellitus, hypertension, dyslipidemia, arrhythmia, alcohol and smoking history), cancerrelated information (types of therapy, presence of systemic metastasis, stage and histologic diagnosis), infarction patterns in brain magnetic resonance image (MRI), initial stroke severity using National Institute of Health Stroke Scale (NIHSS) and initial functional assessments using modified Rankin Scale (mRS) were reviewed in the enrolled patients. The 6-month survival status was reviewed in 52 patients whose medical records were available.

The initial brain MRI and diffusion weighted image were reviewed for infarction lesion pattern. The infarction patterns were classified as followed: 1) single lesion in one vascular territory, 2) scattered lesion in one vascular territory, 3) borderzone infarction, and 4) infarcts involving multiple vascular territories of the brain [11]. In order to rule out artery-to- 
artery embolism, scattered lesions in the same vascular territory were separately categorized from scattered lesions in the multiple vascular territory [12]. Multi-territorial infarction was defined as multiple acute infarctions either in bilateral vascular territory or in anterior and posterior circulations [13]. A retrospective medical record review at our institution was conducted after approval from the Institutional Review Board (IRB) for conducting research and registered under number 2019AN0184.

\section{Statistical analysis}

Categorical variables between two groups were compared using $\chi^{2}$ or Fisher's exact test. The Mann-Whitney U test was used to analyze the differences between two independent groups with non-parametric variables. And the Student's t-test for parametric variables. Six-month survival status was analyzed with Kaplan-Meier survival analysis using the log-rank test and forward conditional (variable entry and removal with $\mathrm{p}<0.05$ ) Cox proportional hazards multi-variate regression models were used to calculate the hazard ratios (HRs) and 95\% confidence intervals (CI). Statistical Package for the Social Sciences (SPSS) version 24.0 (IBM, Chicago, IL, USA) was used for the statistical analysis. A p value of 0.05 or less was considered statistically significant.

\section{RESULTS}

\section{General characteristics of patients}

A total of 63 patients were enrolled with diagnosis of IS with underlying malignancy. This accounts for $0.16 \%$ of total cancer patients from our center during the study period. The demographics, comorbidities and clinical characteristics of the cancer patients with IS are given in Table 1 . The mean age was 74.9 years $( \pm 9.2)$ and 33 patients $(52.4 \%)$ were men. More than half of the patients $(56.0 \%)$ had systemic metastasis and stage 4 cancer was most common (57.1\%). The 32 patients $(50.8 \%)$ had received chemotherapy prior to stroke and two-thirds of the patients were treated with the platinum-based agent as the latest agent before stroke. The neuroradiologic findings revealed 29 patients (44.6\%) with single territory infarction, 7 patients $(10.8 \%)$ with borderzone infarction and 6 patients $(9.5 \%)$ for scattered territorial and 21 patients $(32.3 \%)$ with multi-territorial infarction. The median initial NIHSS score was 3 (0-24), and the median initial mRS score was $3(0-5)$.

\section{Clinical characteristics of cancer and stroke}

The three most frequent types of the primary cancer in the enrolled patients were lung (27.0\%), gastric (14.3\%), colorectal (12.7\%) cancer followed by hepatobiliary $(12.7 \%)$, genitourinary (11.1\%), pancreatic $(6.3 \%)$ and breast $(1.6 \%)$ cancer. Most patients had solid tumors in the enrolled group. The types of cancer in total cancer patients from our center during the study period were in the order of thyroid (14.6\%), colorectal $(11.2 \%)$, gastric $(9.0 \%)$, followed by breast (7.0\%), liver (5.1\%) and lung (4.2\%) (Fig. 1 ).

Histologically, adenocarcinoma was the most common type with 47 patients (74.6\%) followed by hepatocellular carcinoma, small cell lung cancer and lymphoma. Among the adenocarcinoma histology lung, gastric, biliary duct and pancreas and colorectal were the most common cancer types (Fig. 1). We compared the variables between adenocarcinoma or non-adenocarcinoma group and the results were shown in Table 1. The adenocarcinoma group showed lower rates of stroke related comorbidities (dyslipidemia and smoking history, $\mathrm{p}<0.05)$ and multi-territorial infarctions were more common $(\mathrm{p}<0.05)$. The $\mathrm{D}$-dimer levels 
Table 1. Clinical findings in cancer patients with ischemic stroke

\begin{tabular}{|c|c|c|c|c|}
\hline Variable/clinical finding & Total $(n=63)$ & Adenocarcinoma group $(n=47)$ & Non-adenocarcinoma group $(n=16)$ & $p$ value \\
\hline \multicolumn{5}{|l|}{ Demographics } \\
\hline Age (yr), mean (SD) & $74.9(9.2)$ & $75.2(8.2)$ & $73.9(12.0)$ & 0.71 \\
\hline Sex, male, No. (\%) & $33(52.4)$ & $22(46.8)$ & $11(68.7)$ & 0.13 \\
\hline \multicolumn{5}{|l|}{ Comorbidities, No. (\%) } \\
\hline Diabetes mellitus & $24(38.1)$ & $18(38.3)$ & $6(37.5)$ & 0.96 \\
\hline Hypertension & $36(57.1)$ & $24(51.1)$ & $12(75.0)$ & 0.09 \\
\hline Dyslipidemia & $26(41.3)$ & $15(31.9)$ & $11(68.8)$ & 0.01 \\
\hline Arrhythmia & $14(22.2)$ & $12(25.5)$ & $4(25.0)$ & 0.97 \\
\hline Alcohol & $21(33.3)$ & $14(29.8)$ & $7(43.7)$ & 0.31 \\
\hline Smoking & $18(28.6)$ & $9(19.1)$ & $9(56.3)$ & 0.01 \\
\hline \multicolumn{5}{|l|}{ Cancer status, No. (\%) } \\
\hline Systemic metastases & $34(54.0)$ & $26(55.3)$ & $8(50.0)$ & 0.71 \\
\hline \multicolumn{5}{|l|}{ Cancer stage } \\
\hline Stage 1 & $13(20.6)$ & $8(17.0)$ & $5(31.3)$ & 0.22 \\
\hline Stage 2 & $4(6.3)$ & $3(6.4)$ & $1(6.3)$ & 0.99 \\
\hline Stage 3 & $10(15.9)$ & $9(19.1)$ & $1(6.3)$ & 0.22 \\
\hline Stage 4 & $36(57.1)$ & $27(57.4)$ & $9(56.3)$ & 0.93 \\
\hline Chemotherapy & $32(50.8)$ & $24(51.1)$ & $8(50.0)$ & 0.94 \\
\hline Platinum based agents & $26(41.3)$ & $21(44.7)$ & $5(31.3)$ & 0.12 \\
\hline Others & $6(9.5)$ & $3(6.4)$ & $3(18.8)$ & 0.71 \\
\hline Radiotherapy & $10(15.9)$ & $8(17.0)$ & $2(12.5)$ & 0.67 \\
\hline \multicolumn{5}{|l|}{ Multi-territorial Infarctions, No. (\%) } \\
\hline Single vascular territory & $29(46.0)$ & $19(30.2)$ & $10(62.5)$ & 0.16 \\
\hline Scattered & $6(9.5)$ & $4(6.3)$ & $2(12.5)$ & 0.47 \\
\hline Borderzone & $7(11.1)$ & $5(7.9)$ & $2(12.5)$ & 0.15 \\
\hline Multiple vascular territories & $21(33.3)$ & $19(30.2)$ & $2(12.5)$ & 0.04 \\
\hline \multicolumn{5}{|l|}{ Laboratory findings } \\
\hline D-dimer (ug/mL) & $4.49 \pm 5.87$ & $5.51 \pm 6.54$ & $1.75 \pm 1.64$ & $0.37^{*}$ \\
\hline Initial NIHSS, median (SD) & $3(6.3)$ & $4(6.0)$ & $3(7.2)$ & 0.49 \\
\hline Initial mRS, median (SD) & $3(1.6)$ & $3(1.6)$ & $3(1.6)$ & 0.46 \\
\hline
\end{tabular}

SD, standard deviation; NIHSS, National Institutes of Health Stroke Scale; mRS, modified Rankin Scale.

${ }^{*} \mathrm{D}$-dimer data of 4 patients were missing, 3 patients in adenocarcinoma group and 1 patient in non-adenocarcinoma group.

were studied in 59 patients among the 63 enrolled patients and 4 patients ( 3 patients in adenocarcinoma, 1 patient in non-adenocarcinoma group) were not evaluated with D-dimer as part of their acute stroke evaluation. In an analysis of 59 patients, the average D-dimer level in adenocarcinoma group was $5.51 \pm 6.54 \mathrm{mg} / \mathrm{L}$, whereas the non-adenocarcinoma group was $1.75 \pm 1.64 \mathrm{mg} / \mathrm{L}(\mathrm{p}<0.05)$. No significant differences were noted in initial stroke severity measured by NIHSS and mRS.

\section{Six-month survival rate of patients}

Among the enrolled cohort, 52 out of 63 patients were able to be reviewed with survival status at 6-month after stroke. Eighteen patients (34.6\%) died before 6-month post stroke and most common cancer type was lung cancer (52.9\%). Systemic metastasis and multi-territorial infarction were significantly more common in the mortality group $(\mathrm{p}<0.001)$. And also, the initial NIHSS ( $<$ 0.05) and mRS scores were worse in mortality group ( $<<0.05)$ (Table 2). Adenocarcinoma histology showed some relevance with 6-month mortality but did not meet the statistical significance (Table 2). The common causes of death in 6-month mortality group were infection (33.4\%), cancer related (22.2\%) and cardiorespiratory arrest $(22.2 \%)$ (Table 3). Survival probability was significantly lower in patients with multi-territorial infarction ( $\mathrm{p}<0.001$ ) and systemic metastasis ( $\mathrm{p}<0.001$ ) (Fig. 2). In addition, systemic metastasis (adjusted HR, 6.28), multi-territorial infarction (adjusted HR, 4.35) and initial NIHSS score (adjusted HR, 1.09) were significantly associated with 6-month mortality by multivariate analysis (Table 4). 
A

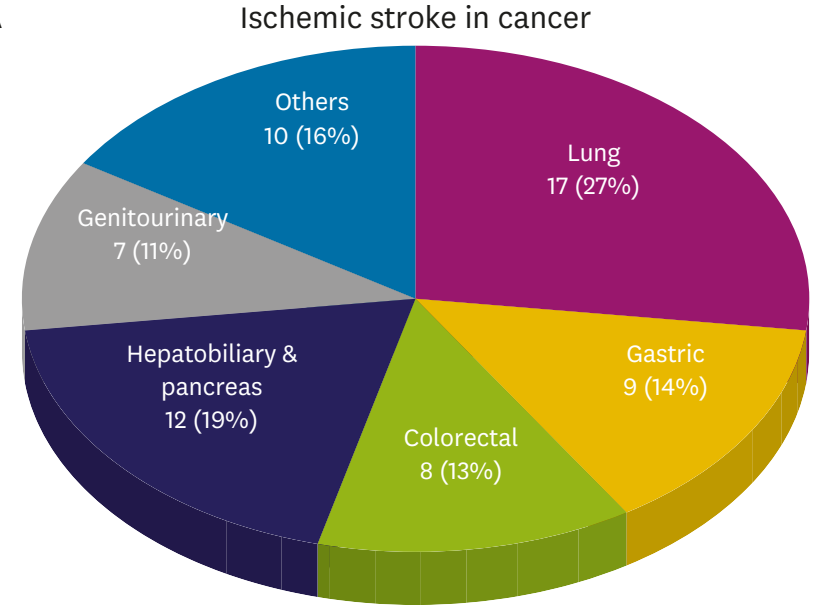

B

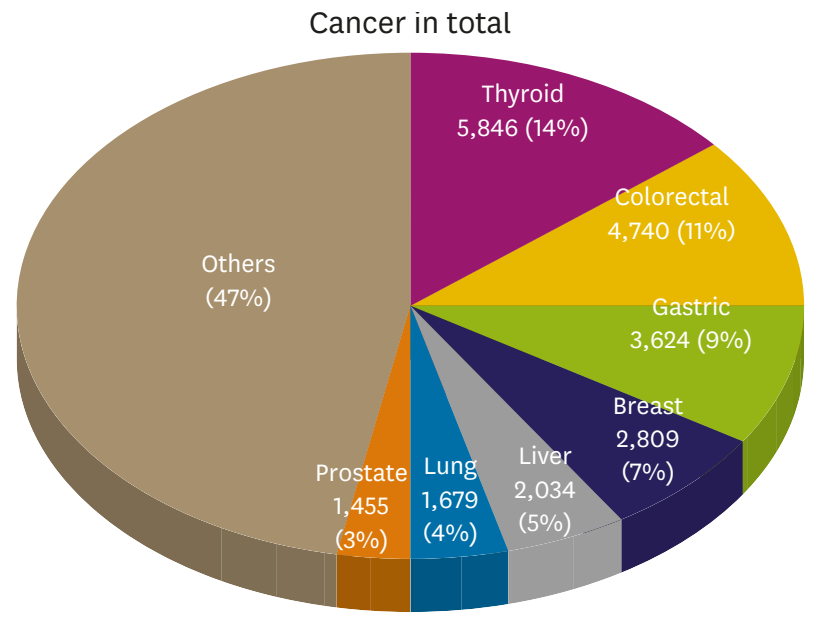

C Histological subtypes

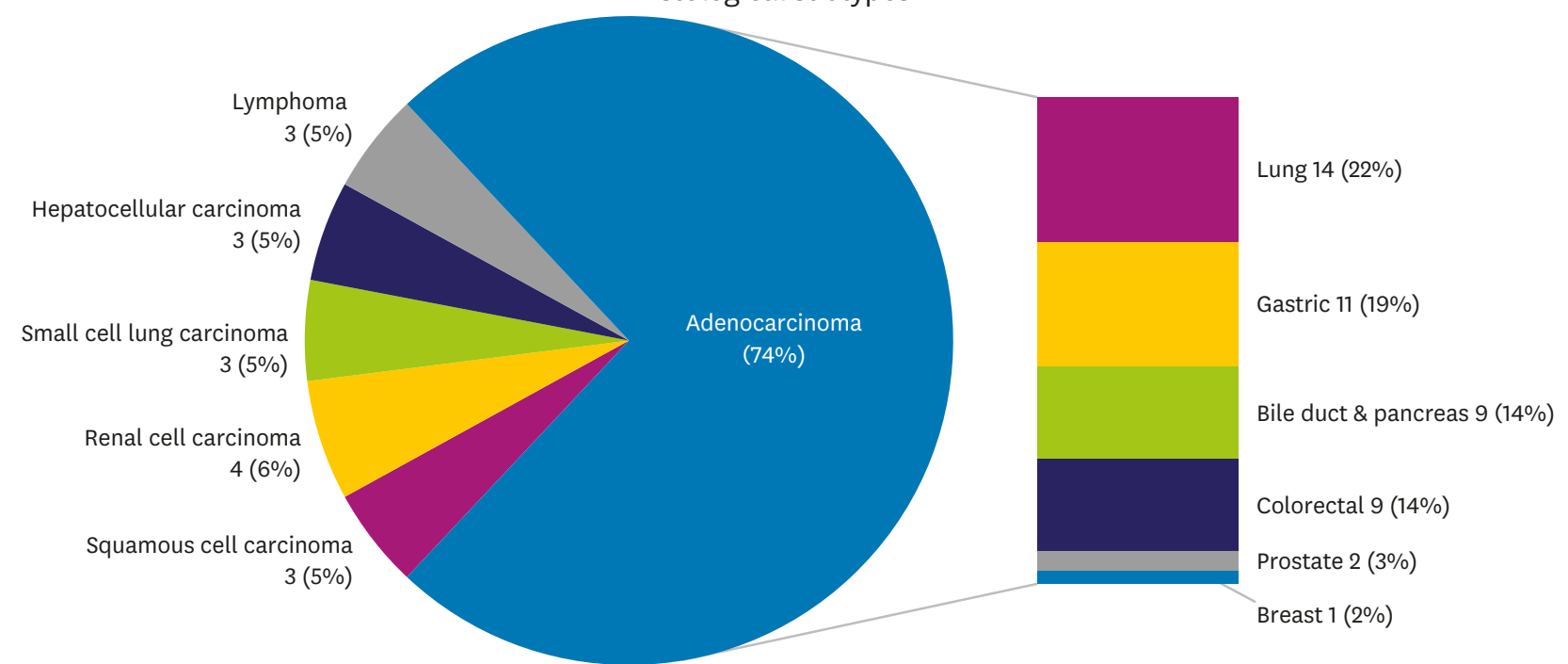

Fig. 1. (A) Cancer types in the enrolled group $(n=63)$, (B) Cancer types in total cancer patients $(n=40,047)$, (C) Histological subtypes of the cancer in the enrolled group $(n=63)$.

Table 2. Survival status at 6-month post-stroke in cancer patients with ischemic stroke

\begin{tabular}{|c|c|c|c|}
\hline \multirow[t]{2}{*}{ Variable/clinical findings } & \multicolumn{2}{|c|}{ Status at 6 -month $(n=52)$} & \multirow[t]{2}{*}{$p$ value } \\
\hline & Dead $(n=18)$ & Alive $(n=34)$ & \\
\hline \multicolumn{4}{|l|}{ Demographics } \\
\hline Age (yr), mean (SD) & $75.1(6.2)$ & $74.8(9.8)$ & 0.88 \\
\hline Sex, male, No. (\%) & $10(55.6)$ & $13(38.2)$ & 0.23 \\
\hline \multicolumn{4}{|l|}{ Cancer status, No. (\%) } \\
\hline Systemic metastases & $16(88.9)$ & $11(32.4)$ & $<0.01$ \\
\hline Adenocarcinoma & $16(88.9)$ & $23(67.6)$ & 0.09 \\
\hline \multicolumn{4}{|l|}{ Infarct patterns, No. (\%) } \\
\hline Multiple vascular territories & $11(61.1)$ & $3(8.8)$ & $<0.01$ \\
\hline Initial NIHSS score, median (SD) & $6(5.6)$ & $2.5(5.1)$ & 0.02 \\
\hline Initial mRS score, median (SD) & $4(1.5)$ & $3(1.5)$ & 0.02 \\
\hline
\end{tabular}

SD, standard deviation; NIHSS, National Institutes of Health Stroke Scale; mRS, modified Rankin Scale. 
Table 3. Causes of mortality in 6-month mortality group

\begin{tabular}{ll}
\hline Causes of death & No. (\%) \\
\hline Infection & \\
$\quad$ Pneumonia & $5(27.8)$ \\
$\quad$ Sepsis (gastrointestinal) & $1(5.6)$ \\
Cancer related & $4(22.2)$ \\
Cardiorespiratory arrest & $4(22.2)$ \\
Stoke related & $3(16.7)$ \\
Renal failure & $1(5.6)$ \\
Total & 18 \\
\hline
\end{tabular}

Table 4. HRs for 6-month mortality after stroke diagnosis.

\begin{tabular}{|c|c|c|c|}
\hline \multirow[t]{2}{*}{ Variable/clinical findings } & \multicolumn{3}{|c|}{ 6-month mortality } \\
\hline & Univariate $\mathrm{HR}(95 \% \mathrm{Cl})$ & Multivariate $\mathrm{HR}(95 \% \mathrm{Cl})$ & $p$ value \\
\hline \multicolumn{4}{|l|}{ Cancer status } \\
\hline Systemic metastases & $6.54(1.88-22.75)$ & $6.05(1.68-21.76)$ & $<0.01$ \\
\hline \multicolumn{4}{|l|}{ Infarct patterns } \\
\hline Multiple vascular territories & $5.87(2.17-15.87)$ & $4.98(1.80-13.76)$ & $<0.01$ \\
\hline Initial NIHSS score & $1.10(1.03-1.17)$ & $1.09(1.01-1.17)$ & $<0.05$ \\
\hline
\end{tabular}

Age, sex, systemic metastasis, adenocarcinoma histology, stroke risk factors, NIHSS, mRS and involvement of multiple vascular territories were adjusted for in the multivariate model using a forward conditional method. NIHSS, National Institutes of Health Stroke Scale; HR, hazard ratio; Cl, confidence interval; mRS, modified Rankin Scale.

\section{DISCUSSION}

Cancer-related stroke is known to differ from stroke without cancer in many aspects. Understanding its etiology and characteristics is important for prevention and effective management. Our study showed different distributions of common cancer types between cancer-related stroke and general cancer groups. In addition, adenocarcinoma patients

A

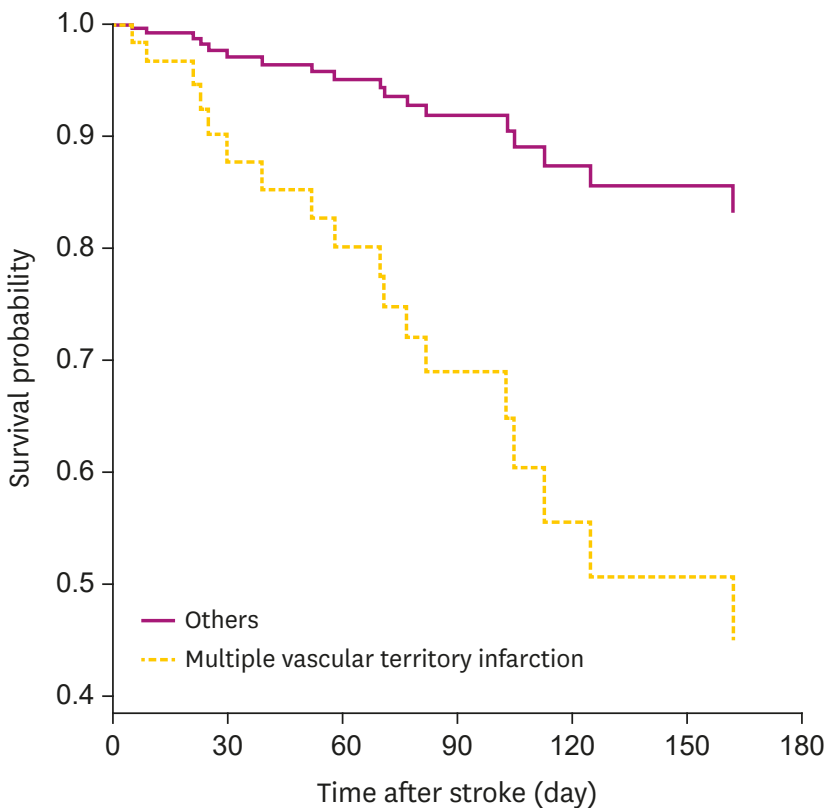

B

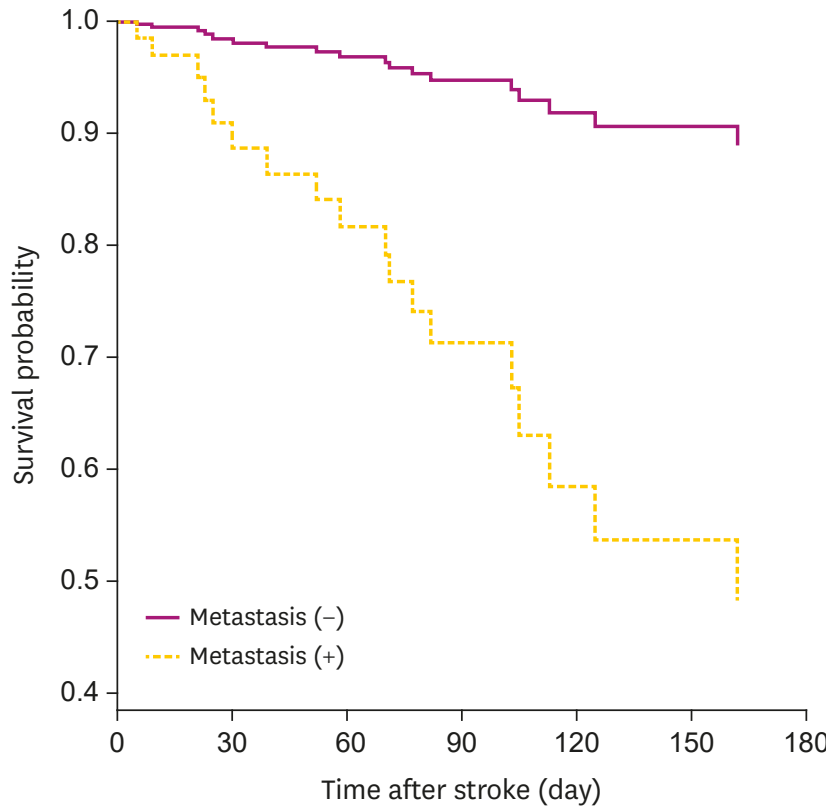

Fig. 2. Kaplan-Meier survival curves stratified by (A) multi-territorial infarction and (B) systemic metastasis within 6-months after stroke (Log-rank test $p<0.001$ for both). 
showed less relevance with conventional stroke risk factors and the multi-territorial infarction patterns were more common in comparison with non-adenocarcinoma patients. The mortality outcome was poor and different features of stroke and underlying cancer influenced the 6-month mortality.

The three most frequent types of the primary cancer in the enrolled group were lung $(27.0 \%)$, gastric $(14.3 \%)$ and colorectal $(12.7 \%)$. However, in total cancer patients, thyroid was the most common cancer type and lung cancer only accounted for $4 \%$. That thyroid cancer is the most common type is not surprising given its highest incidence rate in the nationwide cancer statistics in 2015 [14]. This discrepancy in common cancer types between the cancer related stroke and total cancer group is consistent with previous studies and this may support the idea that certain types of cancer have stronger correlations with stroke [15]. In our study, lung, gastric, bile duct and pancreas and colorectal cancer, which are the common cancer types in enrolled group, were mostly comprised of adenocarcinoma histology (Fig. 1C). And the discrepancy in common cancer types may have resulted from the relationship between adenocarcinoma and IS that has been delineated in the previous studies.

Although still in controversy, the etiology of IS in cancer patients seems to be different from that of stroke without cancer. A multicenter study in Korea reported that nearly $40 \%$ of the cancer patients with IS were assigned to the cryptogenic origin, whereas only $18 \%$ were cryptogenic in conventional stroke group [16]. In addition, the cancer related cryptogenic stroke patients displayed different clinical features from non-cancer patients with fewer atherosclerotic risk factors, coagulation abnormalities such as D-dimer levels, and low nutritional status [17]. Mucin-producing malignancies (e.g., adenocarcinoma) is one of the cancer-related conditions that leads to hypercoagulability and eventually raises the risk of thromboembolism [18]. Despite of missing data of 4 patients, D-dimer levels which represents the measure of activated coagulation were relatively high among the adenocarcinoma group in our study. And the conventional stroke risk factors such a dyslipidemia and smoking were less frequent in adenocarcinoma group and hypertension also showed tendency to be less frequent. As in most studies, there is a direct relationship between cholesterol levels and IS [19]. And a strong dose-response relationship was found between smoking and the risk of stroke, even in young population [20]. Considering this tendency of elevated D-dimer level and having less conventional atherosclerotic risk factors, it may leads us to consider that mucin producing malignancies such as adenocarcinoma could influence the cancer related mechanisms in development of stroke.

Our results showed that multi-territorial infarction pattern was more common in adenocarcinoma patients. In general, multi-territorial infarctions are known to have embolic etiologies. In the case reports on cervical cancer, lung cancer and cholangiocarcinoma patients with episodes of multi-territorial infarction, cardio-embolic work-up was nonremarkable and it was suggested that cancer related thromboembolic events are likely to have caused the deteriorating event [21-23]. And cancer related hypercoagulability accounted for $75 \%$ of multi-territorial infarction cases when the identifiable embolic source was absent [8]. This further supports the idea that adenocarcinoma is associated with thromboembolism and implicates that the mechanism of the cancer-related stroke is different from that of conventional stroke.

Although stroke mortality is gradually declining, it still remains high and it is the third major cause of death in South Korea [24]. In the large cohort study on IS, 78\% of the patients were 
still alive during the 6-month period after the stroke diagnosis [25]. In comparison with this result, the 6-month mortality rate was higher (34.6\%) in our study and it supports the previous literatures describing the poorer prognosis and higher mortality with concurrence of stroke and cancer [11]. It has been described in a recent retrospective study that metastasis and cancer types were significantly associated with 6-month post stroke mortality [26]. The 6-months period was specifically determined based on American Heart Association/ American Stroke Association guidelines that recommend the treatment of stroke with malignancy only for patients with the life expectancy of 6-months or longer [27]. In our study, systemic metastasis, multi-territorial infarction and initial stroke severity were the risk factors for 6-month mortality after stroke. Systemic metastasis places cancer in stage 4 , which may lead to low performance status and underlying disability before the diagnosis of stroke. And the patients with pre-existing disability had higher chances of unfavorable outcome in stroke and also high risk of pneumonia-related mortality [28,29]. Most of the mortalities in our study were due to non-neurological causes such as infection (33.4\%) followed by cancer related and cardiorespiratory causes. In a large cohort study in Japan with IS patients, cerebrovascular was the overall leading cause of death, while pneumonia was the leading cause of death in more disabled sub-group [30]. In line with pneumonia being the most common cause of death in our group, these findings may indicate that widespread advanced cancer status might have influenced mortality. But, since stroke related features such as multi-territorial infarction and stroke severity showed independent correlations with mortality outcomes [25], future studies are warranted with larger cohort to elaborate on the prognostic factors of stroke mortality outcomes.

There are some limitations of this study. First, this study was based on retrospective analysis of clinical data, thus several clinical and functional outcomes data were missing in many patients. Secondarily, the patient data was retrieved from a single medical center and the total number of subjects was small. Therefore, subgroup analysis between cancer and noncancer group and between the cancer types in adenocarcinoma histology was limited. And the potential confounding factors from cancer itself and the characteristics of each cancer type on clinical characteristics of stroke were not taken into consideration. In the future, a multi-center based and well-controlled cohort with a larger patient group is required.

In conclusion, frequent cancer types were different between stroke with cancer and total cancer group and lung cancer was the most common type in the former group. Adenocarcinoma was the most common histologic type and the adenocarcinoma group was associated with having less conventional stroke risk factors and multi-territorial infarction patterns. Six-month mortality outcomes were poor, which was influenced by systemic metastasis, multi-territorial infarction and initial neurological severity.

\section{REFERENCES}

1. Statistics Korea. Cause of death statistics [Internet]. Daejeon: Statistics Korea; 2017. Available at http:// kosis.kr [accessed on 19 November 2018].

2. Graus F, Rogers LR, Posner JB. Cerebrovascular complications in patients with cancer. Medicine (Baltimore) 1985;64:16-35. PUBMED | CROSSREF

3. Caine GJ, Stonelake PS, Lip GY, Kehoe ST. The hypercoagulable state of malignancy: pathogenesis and current debate. Neoplasia 2002;4:465-473.

PUBMED | CROSSREF 
4. Adess M, Eisner R, Nand S, Godwin J, Messmore HL Jr, Wehrmacher WH. Thromboembolism in cancer patients: pathogenesis and treatment. Clin Appl Thromb Hemost 2006;12:254-266. PUBMED | CROSSREF

5. Corley AM, Sullivan MJ, Friedman SE, O'Rourke DJ, Palac RT, Gemignani AS. Relation of venous thromboembolism risk to ischemic stroke risk in hospitalized patients with cancer. Am J Cardiol 2019;123:679-683. PUBMED | CROSSREF

6. Navi BB, Singer S, Merkler AE, Cheng NT, Stone JB, Kamel H, Iadecola C, Elkind MS, DeAngelis LM. Recurrent thromboembolic events after ischemic stroke in patients with cancer. Neurology 2014;83:26-33. PUBMED | CROSSREF

7. Schwarzbach CJ, Schaefer A, Ebert A, Held V, Bolognese M, Kablau M, Hennerici MG, Fatar M. Stroke and cancer: the importance of cancer-associated hypercoagulation as a possible stroke etiology. Stroke 2012;43:3029-3034. PUBMED | CROSSREF

8. Finelli PF, Nouh A. Three-territory DWI acute infarcts: diagnostic value in cancer-associated hypercoagulation stroke (Trousseau syndrome). AJNR Am J Neuroradiol 2016;37:2033-2036. PUBMED | CROSSREF

9. Cestari DM, Weine DM, Panageas KS, Segal AZ, DeAngelis LM. Stroke in patients with cancer: incidence and etiology. Neurology 2004;62:2025-2030.

PUBMED | CROSSREF

10. Bates BE, Xie D, Kwong PL, Kurichi JE, Ripley DC, Stineman MG. One-year all-cause mortality after stroke: a prediction model. PM R 2014;6:473-483.

PUBMED | CROSSREF

11. Cutting S, Wettengel M, Conners JJ, Ouyang B, Busl K. Three-month outcomes are poor in stroke patients with cancer despite acute stroke treatment. J Stroke Cerebrovasc Dis 2017;26:809-815. PUBMED | CROSSREF

12. Na SI, Ryu HU, Lee CH, Jang HS, Lee SW, Yang TH, Kwak HS, Chung GH, Jeong SK. Histological evidence of artery to artery embolism from calcified atherosclerotic plaque of carotid artery. J Korean Neurol Assoc 2016;34:150-153. CROSSREF

13. Sorgun MH, Kuzu M, Ozer IS, Yilmaz V, Ulukan C, Cotur Levent H, Tezcan S, Rzayev S, Rawandi A, Bakırarar B, Isikay CT. Risk factors, biomarkers, etiology, outcome and prognosis of ischemic stroke in cancer patients. Asian Pac J Cancer Prev 2018;19:649-653. PUBMED

14. Jung KW, Won YJ, Kong HJ, Lee ES; Community of Population-Based Regional Cancer Registries. Cancer statistics in Korea: incidence, mortality, survival, and prevalence in 2015. Cancer Res Treat 2018;50:303-316. PUBMED | CROSSREF

15. Navi BB, Reiner AS, Kamel H, Iadecola C, Elkind MS, Panageas KS, DeAngelis LM. Association between incident cancer and subsequent stroke. Ann Neurol 2015;77:291-300.

PUBMED | CROSSREF

16. Kim SG, Hong JM, Kim HY, Lee J, Chung PW, Park KY, Kim GM, Lee KH, Chung CS, Bang OY. Ischemic stroke in cancer patients with and without conventional mechanisms: a multicenter study in Korea. Stroke 2010;41:798-801. PUBMED | CROSSREF

17. Gon Y, Okazaki S, Terasaki Y, Sasaki T, Yoshimine T, Sakaguchi M, Mochizuki H. Characteristics of cryptogenic stroke in cancer patients. Ann Clin Transl Neurol 2016;3:280-287. PUBMED | CROSSREF

18. Shao B, Wahrenbrock MG, Yao L, David T, Coughlin SR, Xia L, Varki A, McEver RP. Carcinoma mucins trigger reciprocal activation of platelets and neutrophils in a murine model of Trousseau syndrome. Blood 2011;118:4015-4023. PUBMED | CROSSREF

19. Yaghi S, Elkind MS. Lipids and cerebrovascular disease: research and practice. Stroke 2015;46:3322-3328. PUBMED | CROSSREF

20. Markidan J, Cole JW, Cronin CA, Merino JG, Phipps MS, Wozniak MA, Kittner SJ. Smoking and risk of ischemic stroke in young men. Stroke 2018;49:1276-1278. PUBMED | CROSSREF

21. Bumbea AM, Trăistaru MR, Dinescu ŞC, Bumbea BŞ, Albulescu DM, Niculescu M, Krastev BM, Muşetescu AE, et al. Cervical adenocarcinoma generator of procoagulant status and ischemic stroke. Rom J Morphol Embryol 2017;58:1477-1484.

PUBMED 
22. Suero-Abreu GA, Cheng JZ, Then RK. Multiple recurrent ischaemic strokes in a patient with cancer: is there a role for the initiation of anticoagulation therapy for secondary stroke prevention? BMJ Case Rep 2017;2017:bcr-2016-218105. PUBMED | CROSSREF

23. Wang L, Xu Y, Tuo M, Zhang L, Zhang H, Wang J. Recurrent stroke in a patient of lung cancer without pulmonary mass: a case report. Medicine (Baltimore) 2018;97:e9815. PUBMED | CROSSREF

24. Kim JY, Kang K, Kang J, Koo J, Kim DH, Kim BJ, Kim WJ, Kim EG, Kim JG, Kim JM, Kim JT, Kim C, Nah HW, Park KY, Park MS, Park JM, Park JH, Park TH, Park HK, Seo WK, Seo JH, Song TJ, Ahn SH, Oh MS, Oh HG, Yu S, Lee KJ, Lee KB, Lee K, Lee SH, Lee SJ, Jang MU, Chung JW, Cho YJ, Choi KH, Choi JC, Hong KS, Hwang YH, Kim SE, Lee JS, Choi J, Kim MS, Kim YJ, Seok J, Jang S, Han S, Han HW, Hong JH, Yun H, Lee J, Bae HJ. Executive summary of stroke statistics in Korea 2018: a report from the Epidemiology Research Council of the Korean Stroke Society. J Stroke 2019;21:42-59. PUBMED | CROSSREF

25. Slot KB, Berge E, Sandercock P, Lewis SC, Dorman P, Dennis M; Oxfordshire Community Stroke Project; Lothian Stroke Register; International Stroke Trial (UK). Causes of death by level of dependency at 6 months after ischemic stroke in 3 large cohorts. Stroke 2009;40:1585-1589. PUBMED | CROSSREF

26. Cutting S, Wettengel M, Conners JJ, Ouyang B, Busl K. Three-month outcomes are poor in stroke patients with cancer despite acute stroke treatment. J Stroke Cerebrovasc Dis 2017;26:809-815. PUBMED | CROSSREF

27. Yoo J, Nam HS, Kim YD, Lee HS, Heo JH. Short-term outcome of ischemic stroke patients with systemic malignancy. Stroke 2019;50:507-511.

PUBMED | CROSSREF

28. Powers WJ, Rabinstein AA, Ackerson T, Adeoye OM, Bambakidis NC, Becker K, Biller J, Brown M, Demaerschalk BM, Hoh B, Jauch EC, Kidwell CS, Leslie-Mazwi TM, Ovbiagele B, Scott PA, Sheth KN, Southerland AM, Summers DV, Tirschwell DL; American Heart Association Stroke Council. 2018 guidelines for the early management of patients with acute ischemic stroke: a guideline for healthcare professionals from the American Heart Association/American Stroke Association. Stroke 2018;49:e46-e110. PUBMED | CROSSREF

29. Leker RR, Gavriliuc P, Yaghmour NE, Gomori JM, Cohen JE. Increased risk for unfavorable outcome in patients with pre-existing disability undergoing endovascular therapy. J Stroke Cerebrovasc Dis 2018;27:92-96. PUBMED | CROSSREF

30. Salive ME, Satterfield S, Ostfeld AM, Wallace RB, Havlik RJ. Disability and cognitive impairment are risk factors for pneumonia-related mortality in older adults. Public Health Rep 1993;108:314-322. PUBMED | CROSSREF

31. Kimura K, Minematsu K, Kazui S, Yamaguchi T; Japan Multicenter Stroke Investigators' Collaboration (J-MUSIC). Mortality and cause of death after hospital discharge in 10,981 patients with ischemic stroke and transient ischemic attack. Cerebrovasc Dis 2005;19:171-178. PUBMED | CROSSREF 